\title{
PERSUADING TO REFLECT: ROLE OF REFLECTION AND INSIGHT IN PERSUASIVE SYSTEMS DESIGN FOR PHYSICAL HEALTH
}

\section{Kirsi Halttu \& Harri Oinas-Kukkonen}

\author{
University of Oulu, Finland
}

\section{Authors' Mini-bios:}

Kirsi Halttu (Kirsi.Halttu@oulu.fi) is an information systems researcher and interaction designer with an interest in mobile systems and persuasive technologies; she is a doctoral student in the Oulu Advanced Research on Information Systems (OASIS) research group of University of Oulu, Finland.

Harri Oinas-Kukkonen (Harri.Oinas-Kukkonen@oulu.fi) is a Professor of Information Systems at University of Oulu, Finland, where he heads the Oulu Advanced Research on Information Systems (OASIS) research group. His central research interests include persuasive technology design, behaviour change, user experience, social innovation, and the next generation of the Web. 


\title{
PERSUADING TO REFLECT: ROLE OF REFLECTION AND INSIGHT IN PERSUASIVE SYSTEMS DESIGN FOR PHYSICAL HEALTH
}

\author{
Special issue article
}

\begin{abstract}
Mobile applications and self-tracking devices help us to maintain health and support our goals in changing our behaviors. Most of the tools aim to increase our self-knowledge by providing information upon which to reflect. However, merely spending time reflecting does not always lead to insightful outcomes. In this study surveying users of mobile health and fitness applications $(N=147)$, we have used structural equation modeling to explore the need for and roles of reflection and insight in the persuasive systems design (PSD) model. The findings suggest that both dialogue support and primary task support features influence the need for reflection, paving the way to personal insight. The perceived credibility of the system played different roles for females and males and seemed to originate from different sources. Additionally, we found significant roles for the attitude and unobtrusiveness of the system. This paper contributes to positioning reflective capabilities of a system in the design framework of persuasive systems and makes preliminary suggestions on how to transform the need for reflection into insights. It also exemplifies how to evaluate behavior change technologies by also assessing the psychological outcomes of the intervention.
\end{abstract}

Keywords: persuasive systems design, behavior change technologies, personal informatics, partial least squares, reflection, insight

\section{$1 \quad$ INTRODUCTION}

Physical inactivity is the fourth leading cause of death worldwide. According to an estimation from 2009, $31 \%$ of the world's population is not engaging in the minimum recommended levels of physical activity (Kohl et al., 2012). Physical activity is usually a core element of lifestyle modifications aimed at maintaining good health. According to a recent study of middle-aged Finnish men, physical activity also relates to subjective well-being (Engberg et al., 2015). Therefore, it is not surprising that there are intense technological and commercial interests in helping people to increase their physical activity using self-care tools and mobile technologies. Additionally, smartphone applications and wearable sensors that support physical activity are the foci of extensive development, and due to the lifestyle-changing and habit-forming characteristics of mobile devices in general, they are promising candidates to assist people in living more active lives. Regardless, it is burdensome to change behaviors even with such technological help, and these tools are often abandoned (Hammond, 2014; Ledger \& McCaffrey, 2014). Furthermore, these tools often fail to support the people who need them the most (Herz, 2014), and they are often used by people who already enjoy relatively good health. Commercial products have also been criticized for not being based on any scientifically proven 
behavioral change methodology (Azar et al., 2013) and for only using a few of the available methods (Middelweerd, Mollee, van der Wal, Brug, \& Te Velde, 2014). Thus, we believe that there is still a great deal of untapped potential among evidence-based approaches, both at the consumer and health care levels.

Activity trackers and most of the mobile and web applications intended to support physical activity can be defined as personal informatics tools. Such personal informatics tools "help people collect personally relevant information for the purpose of self-reflection and gaining self-knowledge" (Li, Dey, \& Forlizzi, 2010; italics original). The related stage-based model of personal informatics has five stages: preparation, collection, integration, reflection, and action. The essence of these tools is the collection of the information necessary for insightful reflection; accordingly, the reflection stage has been the dominant focus of recent research (see, e.g., Baumer, 2015; Li, Dey, \& Forlizzi, 2011). Advances in technology have made the phases more effortless, since most consumer products such as activity trackers collect data automatically and have their own applications that can be utilized for reflecting on the personal data. However, the road to successful and lasting behavioral changes has not yet been found. Interactive persuasive systems (Spagnolli, Chittaro, \& Gamberini, 2016), information systems designed with the intent to change users' attitudes and behaviors, suggest that the key approach to changing behaviors is persuasion (Oinas-Kukkonen \& Harjumaa, 2009). Persuasive systems leverage the potential of technology to exert influence on their users in open and ethically sound ways, without coercion or deception. The persuasive systems design (PSD) model, a conceptual framework for analyzing, designing, and evaluating these systems, builds on theories related to behavior change from both psychology and computer science. Numerous systems and applications have been evaluated using the PSD model as a conceptual framework (Lehto \& Oinas-Kukkonen, 2011 \& 2015; Matthews, Win, Oinas-Kukkonen, \& Freeman, 2016) or by applying a rigorous statistical analysis utilizing constructs derived from the model (Lehto, Oinas-Kukkonen, \& Drozd, 2012; Lehto, Oinas-Kukkonen, Pätiälä, \& Saarelma, 2012; Lehto \& OinasKukkonen, 2015). Increasing an individual's awareness of his/her own actions by encouraging self-monitoring and enabling reflection is also one of the main support functions in the PSD model and one of the principles in the primary task support category (Oinas-Kukkonen \& Harjumaa, 2009).

Any directional change involves self-reflective practices that lead to self-evaluation (or insights). Spending time in self-reflection does not always lead to insightful results, because self-reflection and insight are logically independent activities (Grant, 2003). On the other hand, participation in reflective coaching program can enhance personal insight (Grant, 2008). While the consensus seems to be that reflection is a useful and desirable activity for the user, it remains unclear how the reflective capacity of the system should be evaluated and how individual differences in terms of the ability to self-reflect and form insights manifest. In the context of interactive persuasive systems, these issues should be the foci of intensive research. We propose that if any system has the potential to induce changes in behavior and/or attitude, such changes should be visible at the relevant level of metacognition. In this explorative study of regular users of physical activity support systems, 
we have measured the persuasive features of the systems that participants were using, along with users' levels of need for self-reflection (hereafter: "need for reflection") and insight. This study aims to understand whether the psychological constructs of reflection and insight can be utilized in understanding the change process and assessing the reflective power of the system.

RQ: Do system features of the PSD model have influence on users' need for self-reflective practices?

This paper is structured as follows. In the next section, we outline the design landscape of those systems aimed at behavior change and discuss the theory behind reflection and insight. Then, we present our research model, constructs, and hypotheses based on the existing literature. After the results of the model analysis are presented, we discuss some of the study's main findings and offer some final conclusions.

\section{THEORETICAL BACKGROUND}

\subsection{Reflection in design practice}

The reflection phase is the most studied element of the stage-based model of personal informatics, and the corresponding behavior change technique, self-monitoring, is one of most commonly used and effective approaches to change (Michie, Abraham, Whittington, McAteer, \& Gupta, 2009). Self-monitoring is one type of self-regulation technique, along with goal setting and feedback. Self-tracking refers to the use of sensors, either in a wearable device or in a mobile phone, to assist in both self-monitoring and data gathering. Using personal data from mobile wellness- and health-related applications and wearables, people are expected to increase their self-awareness by making their behaviors visible and identifying correlations between actions and outcomes. The HCI (human-computer interaction) community has responded to the challenges of reflection in various ways. For example, the theoretical basis of reflection (Fleck and Fitzpatrick, 2010) was assembled into a conceptual framework that is more in touch with design practices. Furthermore, Baumer (2015) introduced the notion of reflective informatics and identified dimensions of reflection for guiding the design of reflective technologies. These theoretical groundings have subsequently served as the basis for numerous research activities (for a review of these activities, see Baumer et al., 2014). The focus of these activities has ranged from designing technology that facilitates "glanceable" feedback, which highlights how valuable and short our attention span is (Gouveia, Pereira, Caraban, Munson, \& Karapanos, 2015), to slow technology. Slow design leaves space for reflection and urges designers to recognize the complexity of the change process (Siegel \& Beck, 2014). Additionally, recent studies have acknowledged the ability to create habits (Stawarz, Cox, \& Blandford, 2015) and have also covered the utilization of automatic and subliminal stimuli (Adams, Costa, Jung and Choudhury, 2015). Lately, personalization as a result of the user's own reflective practices has shown promise as an approach (Lee, Kim, Forlizzi and Kiesler, 2015). The desired change is often difficult and takes a considerable amount of time, but the aforementioned approaches exemplify 
the already existing contribution to our understanding of future solutions. Both fast-glancing and reflectioninducing slow technologies emphasize the essence of proper, contextualized visualizations, and both approaches can be utilized in the same solutions. For instance, for "reflection-in-action," the user needs to use time-critical information when active, while "reflection-on-action" refers to reviewing the data later with more time and consideration. Both approaches are usable, for example, in heart rate monitors and activity trackers. Indeed, many tools provide support for both the reflection-in-action and reflection-on-action varieties of data viewing (Ploderer, Reitberger, Oinas-Kukkonen, \& van Gemert-Pijnen, 2014). It is of outmost importance to envision solutions as tailored combinations of several different approaches, not as contradictory streams. However, not all people are willing or able to create insightful and actionable items based on their data. This might be partly due to individual differences in motivations and goals or in the ability to self-reflect in general.

\subsection{From reflection to insights}

Increasing an individual's awareness of his/her automatic thought and behavior processes is a fundamental principle of cognitive behavioral therapies. Self-reflection, "the inspection and evaluation of one's thoughts, feelings and behavior," is a metacognitive factor of the self-regulation process, and it is often associated with directional behavioral change (Grant, Franklin, \& Langford 2002). Reflecting on one's progress and developing levels of personal insight are required in the process of being coached (Grant, 2008), but reflection and insight are considered to be logically independent. Moreover, insight is not always the result of reflective actions. Reflection itself does not have valence, and therefore, the results of reflection can be either problem solving and constructive or, in the presence of a dysfunctional attitude, even ruminative (Stein \& Grant, 2014). Rogers (2001) reviewed the existing higher education research and summarized that reflection is concerned with understanding one's experiences and then integrating this understanding into future choice making. Reflection is active and purposeful, and it requires engagement, but the nature of one's engagement in conscious reflection might lead to different outcomes. Additionally, reflection is most likely to comprise two types of reflection: self-focused reflection and problem solving reflection, of which the problem solving type is more likely to lead to insightful results (Grant et al., 2002). The concept of insight is defined differently in different disciplines, but in this study we aim to address the metacognitive factor defined as "clarity of understanding of one's thoughts, feelings and behaviour" (Grant et al., 2002). This particular description refers to self-insight, which is different from cognitive insight, often being described as "aha!" moments. Self-insight is considered an essential part of purposeful change and is one mechanism of cognitive and behavioral therapies (Stein \& Grant, 2014). In this paper, we use the term insight as the equivalent of self-insight.

The complex nature of reflection makes the support of reflection a challenging task. However, in most reviews the process begins with problem identification and deliberation in order to find a solution. When the necessary information (or in the context of personal informatics, data) is collected, the next step involves planning and 
deciding to act on upon that data. This assumes that the reflection phase changed something in the individual's thinking. The major outcome of reflections should be some level of learning. Mezirow (1991) stated that reflective actions lead to transformative learning, with individuals changing their expectations of their actions and habits and developing more accurate, adjusted perceptions of reality via transformed meaning schemes. These more accurate perceptions can be generated via sensing tools. Overall, interactive technologies are able to create conditions that enable reflection and eventually lead to actionable results for the users. Regardless, there are still numerous challenges in building systems that genuinely succeed in generating lasting changes in behavior, and not all of these challenges are caused by technological difficulties. Eventually, reflection and insight are the responsibilities of the user, and the system can only persuade the user in the direction of certain activities and outcomes.

HCI community has emphasized the importance of reflection but there is no methods to actually measure it. This study aims to address this shortcoming by using psychological constructs of need for reflection and insight in the context of persuasive systems design. The gathered response data is analysed using partial least squares equation modelling (PLS-SEM), a modelling technique that is able to estimate complex causal relationships among several variables at the same time. The study adds to existing knowledge on personal informatics as reflective systems and combines it with interactive persuasive systems.

\section{RESEARCH MODEL AND HYPOTHESES}

The conceptual framework used in this study is the persuasive systems model (Oinas-Kukkonen and Harjumaa, 2009). The PSD model combines existing research from several disciplines into one model to analyze, design and evaluate information systems with persuasive features. The model is based on seven postulates that highlight some key principles behind each persuasive system. The first postulate states that persuasive systems are never truly neutral and always exert some degree of influence on their users, often unintentionally. For their part, the users want to be consistent in their views, and they can be persuaded via either a direct or indirect route, depending on their tendency to elaborate on the information provided. Persuasive systems should also be open in announcing their intentions to influence their users in order to avoid coercion and deception. Further, persuasion is usually incremental by nature. The final postulates state that the system should aim to be unobtrusive, useful, and easy to use. These postulates can be transformed into the software's characteristics and possess mediating powers toward other features. The actual system features are found in the categories of primary task support, dialogue support, system credibility support, and social support. Primary task support refers to features that support the main goal that the system helps users to achieve, and this is often supported by different features from the dialogue support category, such as giving feedback, rewarding, or reminding. System credibility features illustrate how innate persuasive powers of credibility can be leveraged in system design. The fourth category of social support focuses on the effects of social influence. The model also guides 
in analyzing the persuasion context to help us understand the uses, users, and technological factors affecting the system design (Oinas-Kukkonen \& Harjumaa, 2009).

Figure 1 illustrates the research model. All of the relationships between the constructs, represented by arrows, are assumed to be positive. The fundamental work of Lehto and Oinas-Kukkonen (Lehto et al., 2012a; Lehto et al., 2012b; Lehto \& Oinas-Kukkonen, 2014) in developing measurement items and basic models for quantitative research approach was the baseline for this research model. Two hypotheses, $\mathrm{H} 2 \mathrm{~b}$ and H2c, have received support in three previous studies (Lehto et al., 2012a; Lehto et al., 2012b; Lehto \& Oinas-Kukkonen, 2014. They are used as controls to assess that existing knowledge derived from web-based services and studies of one system only is applicable also in our study. The model also brings in three constructs outside the PSD framework: attitude, need for reflection and insight. These constructs were chosen to address the role of attitudinal aspects and reflective elements in existing PSD model.

The research question of this paper focus on newly introduced constructs and aims to find out, if PSD model constructs influence on need for reflection and insight. We also assess predictive relevance of endogenous constructs. Aforementioned analyses are conducted using structural equation modelling (SEM) approach PLSSEM. It has become increasingly popular among information systems and marketing research due to its ability to simultaneously test and estimate causal relationships among multiple constructs, therefore often referred as second generation technique. In addition, SEM is highly applicable to latent variables (aka. constructs) that cannot be measured directly but have to be constructed (Urbach \& Ahlemann, 2010). PLS-SEM is usually considered most efficient for exploratory research designs, instead of confirmatory studies. These advantages allow researchers to both assess constructs at the observational level, often referred to as outer or measurement model, and relationships between those constructs on the theoretical level (inner or structural model) (Hair, Sarstedt, Ringle, \& Mena, 2012). The original source of each construct used in this study is available in Appendix I and we introduce related hypotheses in the subchapters below. 


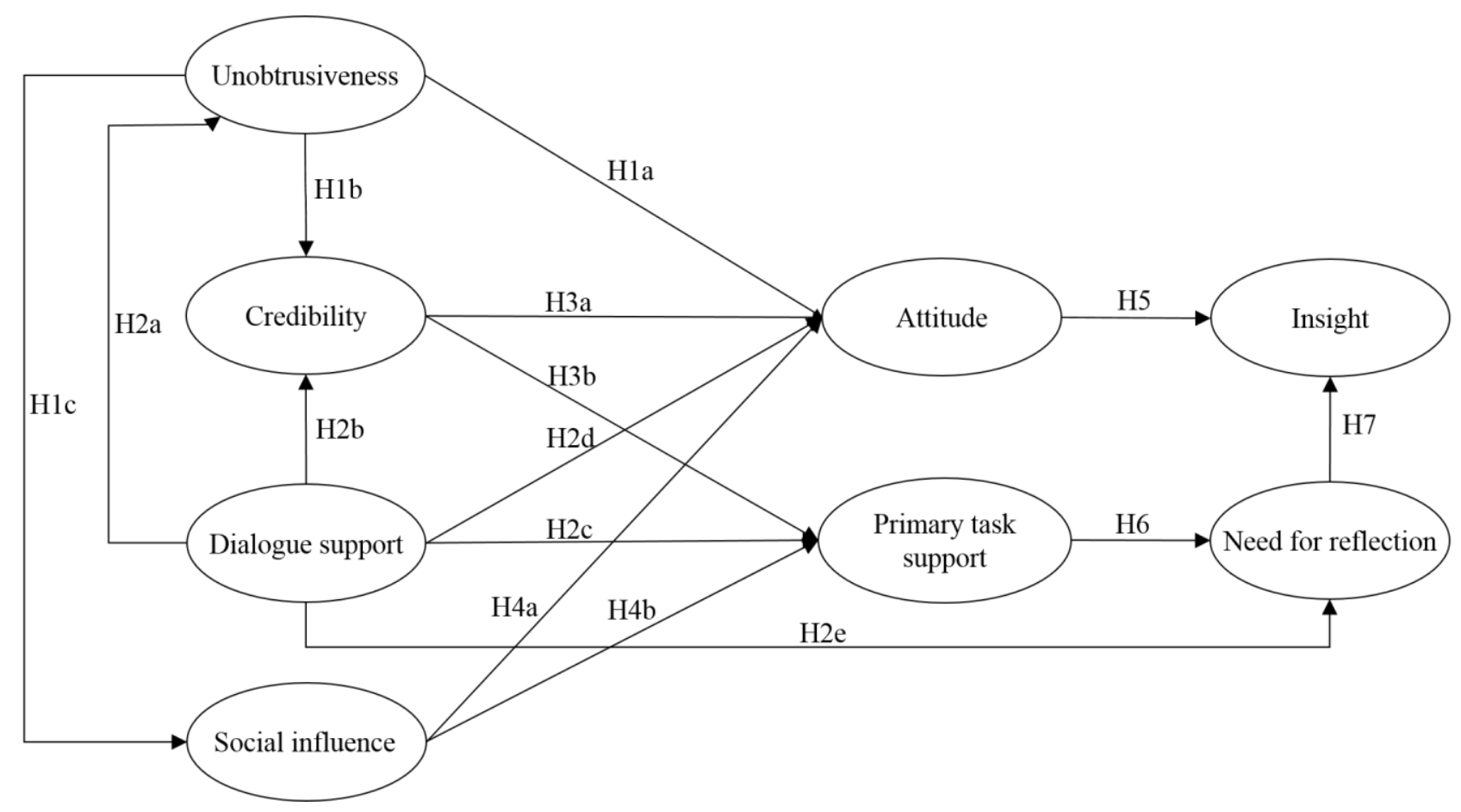

Figure 1. Research model and the hypotheses.

\subsection{Unobtrusiveness}

Lehto et al. (2012a) defined unobtrusiveness as a construct that measures how well the utilized system fits into the actual environment in which it is used. Therefore, questions of unobtrusiveness assess the relations between the system, the user, and the context. Unobtrusiveness is also one of the postulates in the PSD model. When the system fits well with both the environment and the user's needs, it increases the user's positive affect and attitude toward the system, and the user is more inclined to see the system as a reliable and trustworthy source of information. Therefore, we propose:

Hla: Unobtrusiveness will have a positive influence on attitude.

HIb: Unobtrusiveness will have a positive influence on perceived credibility.

An acceptable level of intrusiveness in the use of the system also enhances its acceptability among people other than the user itself, like friends and important ones. Positive changes in the user's behavior and mental state also add to this effect. Thus, we formulated the following hypothesis:

H1c: Unobtrusiveness will have a positive influence on social influence. 


\subsection{Dialogue support}

Dialogue support features facilitate the interaction between the user and the system. Such features aim to support the user in reaching the desired goals and targets (i.e., primary tasks), and the system performs these actions via providing feedback, suggestions, praise, or rewards. Often, the dialogue support features are the most prominent features of the system, and they have a remarkable impact on the user's experience and acceptance of the system. Therefore, the unobtrusiveness of the system is strongly influenced by dialogue support. The corresponding hypothesis is as follows:

H2a: Dialogue support will have a positive influence on unobtrusiveness.

When the dialogue features provide feedback that the user finds useful and reasonable, the perceived trustworthiness and reliability of the information source are enhanced. Previous studies (Lehto et al., 2012a; Lehto et al., 2012b; Lehto \& Oinas-Kukkonen, 2014) imply that dialogue support contributes significantly to perceived credibility. Based on this, we offer the following hypothesis:

H2b: Dialogue support will have a positive influence on perceived credibility.

The interactive features provide the user with support when he/she is completing important and essential tasks (i.e., primary tasks). A well-designed system offers the right kind of support at the right time, and by doing so, it increases the potential to meet the desired goal(s). As previous hypothesis, also the following one has received support in existing literature (Lehto et al., 2012a; Lehto et al., 2012b; Lehto \& Oinas-Kukkonen, 2014).Therefore, we hypothesize:

H2c: Dialogue support will have a positive influence on primary task support.

As a more general result of the interaction, dialogue support affects the overall attitude that the user has toward the system. Hence, the fourth hypothesis regarding dialogue support is:

H2d: Dialogue support will have a positive influence on attitude.

Self-reflection entails evaluation and examination of one's feelings and behaviors with the aim of understanding them. One can assume that an individual aiming to make lasting changes in his/her life will feel some degree of need for self-reflection, as this innate motivation to understand is most likely to lead to successful change. Dialogue support feeds this need by providing feedback, praise, and rewards that could further favor the investment of time in self-reflection. Therefore, we propose the following hypothesis: 
H2e: Dialogue support will have a positive influence on the need for reflection.

\subsection{Perceived credibility}

Perceived credibility is a construct that summarizes several terms relating to credibility, such as trust, believability, and reliability (Lehto et al., 2012a; Lehto et al., 2012b). All of these terms have an impact on users' attitudes toward using the system. Indeed, if the system does not foster trustworthy user experiences, the user will most likely see its use in a less positive light. Based on this, we propose:

H3a: Perceived credibility will have a positive influence on attitude.

A belief in the trustworthiness and reliability of the service also supports the user in his/her primary tasks. If the user trusts the service, he/she is more likely to follow its recommendations and believe that the service helps in reaching the desired goals. Trustworthiness leverages the system's persuasive power (Fogg, 2003) as delivered via the primary task support category features. This brings us to the following hypothesis:

H3b: Perceived credibility will have a positive influence on primary task support.

\subsection{Social influence}

In this context, social influence refers to how people other than the user evaluate the utilized system. To be more specific, the questions measure how the system user perceives the others evaluate it. This construct was chosen to study the overall acceptance of the systems among those surrounding the user, and it does not directly reflect the social support categories of the PSD model. The construct was modified from a gamification study in which social influence significantly influenced both attitudes towards the use of gamification and the perceived amount of social recognition received as feedback (Hamari \& Kuusisto, 2013). If the user perceives that significant individuals and other people value the system he/she is using, it has a positive impact on the user's own perceptions and attitudes:

H4a: Social influence will have a positive influence on attitude.

The positive social influence will also affect how the user perceives the support that the system provides to him/her in reaching his/her personal goals, although this impact might come via several different mechanisms:

H4b: Social influence will have a positive influence on primary task support. 


\subsection{Attitude}

Attitude is a factor of several behavior change related theories, for example Theory of Reasoned Action (Fishbein \& Ajzen, 1975) and Theory of Planned behavior (Ajzen, 1991), and it is often considered an important mediator of behavior. Usually, it is used in the context of behavioral intentions or as a predictor of using or continuing to use a system. In this study, it reflects the user's overall satisfaction with the system used. Importantly, attitude often mediates the impacts of other features. Stein and Grant (2014) studied the role of dysfunctional attitudes (i.e., negatively biased thoughts about oneself, the world, and the future) in relation to self-reflection and insight, and they concluded that self-reflection may impede the formation of insight when dysfunctional attitudes are activated during the reflection process. This study used a general attitude scale and so did not address dysfunctional attitudes with a specific questionnaire. However, we believe that attitudinal elements are part of a successful behavioral change process because they have an impact on the ability to gain insights. We therefore propose:

H5: Attitude will have a positive influence on insight.

\subsection{Primary task support}

The primary task support category of the PSD model comprises the design principles that support the user in completing his/her primary tasks. The scale used in this study measures how well the system supports the user in reaching his/her goals. The primary task support, while supporting the user in reaching his/her goals, also emphasizes those goals in the user's life and puts them in focus. This should increase the need for selfreflection because the user is monitoring his/her behavior and finding associations between his/her current state and behavior. If the primary task support is effective in carrying out its tasks, the following hypothesis is supported:

H6: Primary task support will have a positive influence on the need for reflection.

\subsection{Need for reflection and insight}

Grant (2002) developed the scales for assessing reflection and insight in order to understand the relationships between the metacognitive processes linked to change and monitor systemized change during the change process. The original scale featured a set of questions regarding reflection and insight in which self-reflection was comprised of two factors: the need for reflection and engagement with reflection. (Grant, 2002). Roberts and Stark (2008) found that insight relates significantly to the need for reflection but not to engagement with reflection. Lyke (2009) found that insight also relates to well-being, although there was no significant correlation between insight and engagement with reflection. We used only the need for self-reflection scale because previous research has not found any connection between engagement in reflection and insight. 
From the behavioral change viewpoint, the need to think about one's thoughts, feelings, and behaviors (or the need for reflection) should have some impact on achieving clarity regarding one's thoughts, feelings, and behaviors (i.e., insight). However, the relationship between self-reflection and insight remains unclear. Stein and Grant (2014) reported that a relationship between reflection and insight exists and that insight mediates the influence of reflection on subjective well-being. Grant (2008) found that conscious reflection on their own progress increased personal insight levels of participants in coaching programs. Our hypothesis is that people with an innate or situational need to be self-reflective are also more inclined and motivated to clarify their inner processes and gain insight. Therefore, their need to reflect guides their reflective actions and leads to insight. Thus, we propose:

H7: The need for reflection will have a positive influence on insight.

\section{RESEARCH METHODOLOGY}

\subsection{Instrument development}

All of the study's measurement items are existing constructs. We slightly modified the original wordings to match our study's focus. The final wordings and sources of the measurement items are available in Appendix 1.

\subsection{Subjects and data collection}

An email invitation letter containing the link to the Webropol survey was sent to 18,605 students and employees of the University of Oulu. The introductory text indicated that respondents to the survey should be regular users of any health or well-being services. Some 176 responses were received (a sample rate of $0.95 \%$ ). The actual response rate should, however, be defined based on number of real target users. The use of mobile health and wellness applications is not yet mainstream activity in Finland, and according to recent statistics, only around 22\% has used those services (Suomen virallinen tilasto (SVT), 2015). Further, there is no information on how many of those who have tried these services keep using the service until considered regular users. The validity of the responses was checked, and those responses with low or unclear use of a relevant application and those users of a service/application type not considered to be a health or wellness application were removed from the data set. The final sample contained 147 valid responses. Figure 2 presents the basic demographics of the valid responses. Overall, the respondents were mainly women, under 30 years old, and educated through the undergraduate level. Almost half of all respondents (44.9\% when part-time employees and entrepreneurs were included) were employees, while $51.7 \%$ were university students.

\begin{tabular}{lccc}
\hline & & Frequency & Percent $(\%)$ \\
\hline Gender & Female & 88 & 59.9
\end{tabular}




\begin{tabular}{llcc} 
& Male & 59 & 40.1 \\
Age & $20-29$ & 82 & 55.8 \\
& $30-39$ & 40 & 27.2 \\
Employment status & $40-49$ & 17 & 11.6 \\
& $50-59$ & 8 & 5.4 \\
Highest completed education & Employee & 66 & 44.9 \\
& Student & 76 & 51.7 \\
& Other & 5 & 3.4 \\
& Secondary school & 27 & 18.4 \\
& Polytechnic & 7 & 4.8 \\
& Bachelor's degree & 44 & 29.9 \\
& Master's degree & 50 & 34.0 \\
& Doctor's degree & 16 & 10.9 \\
\hline
\end{tabular}

Figure 2. Respondent characteristics.

The participants were first asked to list the applications and services they had used. After that, they were asked to select one service as their main service, which was used as the evaluation object in subsequent questions. The most commonly used/tried service was Sports Tracker, followed by Polar Flow and HeiaHeia. These services were also selected most often as participants' main services (Figure 3). The biggest group, "others," included 30 applications/services that were used by one to four respondents each. Based on the Pearson chisquare test, there were no significant differences between men and women, although some services seemed to attract the genders a bit differently. For example, HeiaHeia was more popular among the women, while the men preferred Suunto products and services.

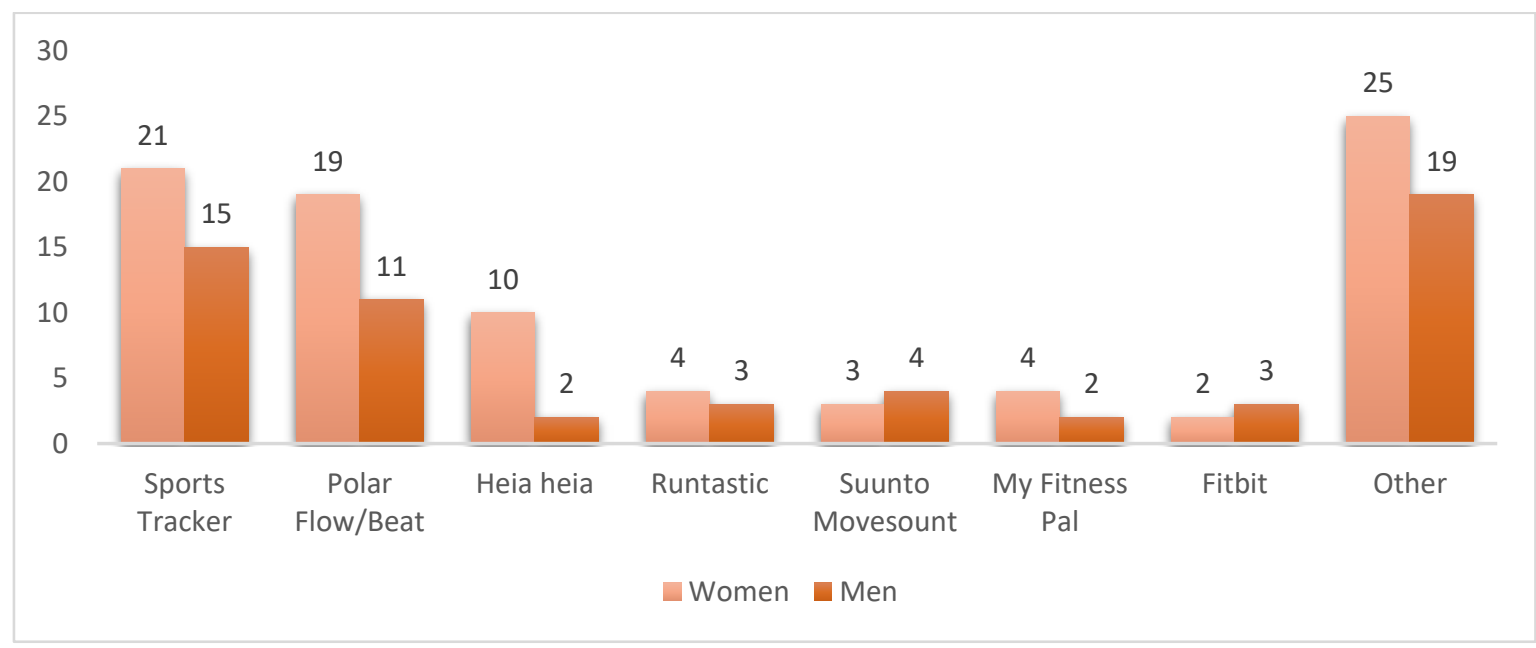

Figure 3. The frequencies of different physical activity applications among the participants.

About half of all respondents (56.4\%) used an additional tracking device, such as a heart rate monitor or a pedometer/activity tracker, alongside their preferred application. The genders differed only slightly, with $49.5 \%$ of women and $54.1 \%$ of men using an additional tracking device. The most popular devices were Polar 
heart rate monitors and activity trackers, followed by Suunto products. There were no significant differences in the use of trackers between men and women or between those of different occupational statuses.

In general, women were more frequent users of their preferred service (most commonly using the service once or several times per day). Some $81.7 \%$ of women used their service several times per week or more, compared to $75.4 \%$ of men (Figure 4 ). About $70 \%$ used the service via a mobile application, compared to only $8.2 \%$ via web browser. However, 21.8\% used both applications and browsers, with dual use being well-supported in some services, such as Polar Flow.

\begin{tabular}{llll}
\hline & & Frequency & Percentage $(\%)$ \\
\hline Use frequency & Several times a day & 16 & 10.9 \\
& About once a day & 31 & 21.1 \\
& Several times a week & 70 & 47.6 \\
Service used & About once a week & 15 & 10.2 \\
& Several times a month & 15 & 10.2 \\
& About 2 months & 15 & 10.2 \\
& $3-5$ & 27 & 18.4 \\
& $6-11$ & 29 & 19.7 \\
& $12-24$ & 37 & 25.2 \\
& Over two years & 39 & 26.5 \\
\hline
\end{tabular}

Figure 4. The characteristics of use of the systems.

We created subgroups based on our prior knowledge of the systems in order to explore the data set further. The groupings concerned gender, age, and the length and frequency of the participants' use of the systems. All groupings contained two groups to maintain sufficient sample sizes. For gender, the two groups were females and males. For system use, we divided the participants into two groups based on the length of system use: up to 12 months of use and over 12 months of use. The frequency groups were divided into daily users (using the service either several times per day or about once a day) and weekly users (using it several times per week, once a week, or several times a month). For age, there were groups for participants under 30 years old and another for those 30 years and older.

The descriptive statistics (mean and standard deviation) for all the constructs and subgroups are presented in Figure 5. We analyzed the distributions between subgroups using the Mann - Whitney U test for independent samples. There were several statistically different distributions among the subgroups. Firstly, the values for unobtrusiveness, social influence, and the need for self-reflection had different distributions between females and males. In addition, users under 30 years of age had a different distribution for primary task support than 
those aged 30 years and older. All of our constructs showed non-normal distributions when checked using the Shapiro - Wilk test in IBM SPSS Statistics software. Additionally, primary task support and attitude had relatively high skewness (-1.161 and -1.168 , respectively) and kurtosis (1.595 and 1.860, respectively).

\begin{tabular}{|c|c|c|c|c|c|c|c|c|c|}
\hline \multirow[b]{2}{*}{ Constructs } & \multirow[b]{2}{*}{ Females } & \multirow[b]{2}{*}{ Males } & \multicolumn{5}{|c|}{ Mean (standard deviation) } & \multirow[b]{2}{*}{$\begin{array}{c}\text { Weekly } \\
\text { users }\end{array}$} & \multirow[b]{2}{*}{$\begin{array}{l}\text { Full } \\
\text { sample }\end{array}$} \\
\hline & & & $\begin{array}{c}\text { Below } 12 \\
\text { months }\end{array}$ & $\begin{array}{c}\text { At least } 12 \\
\text { months }\end{array}$ & $\begin{array}{c}\text { Under } 30 \\
\text { years }\end{array}$ & $\begin{array}{c}30 \text { years and } \\
\text { older }\end{array}$ & Daily users & & \\
\hline UNOB & $5.97(1.29)$ & $\mathbf{5 . 5 1} * *(0.98)$ & $5.73(1.00)$ & $5.84(0.83)$ & $5.91(0.83)$ & $5.64(1.00)$ & $5.94(0.81)$ & $5.72(0.96)$ & $5.79(0.91)$ \\
\hline DIAL & $4.71(1.43)$ & $4.49(1.23)$ & $4.63(1.32)$ & $4.61(1.39)$ & $4.58(1.30)$ & $4.67(1.43)$ & $4.85(1.31)$ & $4.52(1.36)$ & $4.62(1.35)$ \\
\hline CRED & $5.53(0.98)$ & $5.41(1.09)$ & $5.46(1.02)$ & $5.48(1.06)$ & $5.59(0.98)$ & $5.34(1.07)$ & $5.52(1.21)$ & $5.46(0.98)$ & $5.48(1.02)$ \\
\hline SOC & $5.54(1.12)$ & $4.83 * * *(1.16)$ & $5.21(1.24)$ & $5.30(1.14)$ & $5.38(1.18)$ & $5.10(1.18)$ & $5.47(1.05)$ & $5.16(1.24)$ & $5.27(1.19)$ \\
\hline ATT & $5.96(0.91)$ & $5.72(113)$ & $5.83(1,07)$ & $5.89(0.94)$ & $5.92(0.94)$ & $5.78(1.09)$ & $6.04(0.82)$ & $5.78(1.07)$ & $5.86(1.01)$ \\
\hline PRIM & $5.76(1.21)$ & $5.60(1.18)$ & $5.77(1.05)$ & $5.63(1.33)$ & $5.91(1.02)$ & $\mathbf{5 . 4 3} *(1.35)$ & $5.71(1.16)$ & $5.69(1.22)$ & $5.70(1.20)$ \\
\hline NEED & $5.36(1.29)$ & 4.98*(1.14) & $5.27(1.17)$ & $5.15(1.30)$ & $5.34(1.18)$ & $5.05(1.30)$ & $5.47(1.21)$ & $5.09(1.24)$ & $5.21(1.24)$ \\
\hline INSI & $5.20(1.10)$ & $5.04(1.02)$ & $5.08(0.96)$ & $5.18(1.02)$ & $5.15(1.11)$ & $5.10(0.91)$ & $5.36(0.96)$ & $5.02(1.04)$ & $5.13(1.02)$ \\
\hline
\end{tabular}

Figure 5. Descriptive statistics for subgroups and full sample. Significantly different distributions among subgroups are indicated with asterisks $(* p<0.05 ; * * p<0.01 ; * * * p<0.001)$.

\section{RESULTS}

The data were analyzed using structural equation modeling (SEM) that is statistical technique for simultaneously estimating relationships among multiple constructs. Our choice was partial least squares (PLSSEM) approach using SmartPLS software (Ringle, Wende, \& Becker, 2015). Compared to covariance-based SEM (CB-SEM), the variance-based PLS-SEM approach was more suitable for the exploratory research questions that interested us. In addition, our data were non-normally distributed, making the choice of PLSSEM justified (Hair, Hult, Ringle, \& Sarstedt, 2014). PLS-SEM analysis is comprised of two steps. The first step assesses the measurement model that refers to analyzing the relationship of each indicator with their corresponding constructs. In our model, all of the constructs were reflective and measured with at least two indicators. As a rule, reflective measurement models are assessed in terms of their internal consistency reliability and validity. If the measurement model is considered acceptable, second step evaluates the hypothesized relationships between the constructs, i.e. structural model. The evaluation of the predictive capabilities of the structural model is based on the significance of the path coefficients and the relationships between the constructs.

\subsection{Measurement model}

The measurement aspect of the SEM evaluates the reliability and validity of the constructs. In this exploratory study, we placed special emphasis on evaluating the construct's validity measures, and, if necessary, we removed measurement items to reach acceptable levels of validity and reliability. Our questionnaire did not 
allow leaving questions unanswered; therefore, our data set does not contain missing values for any measurement items. The evaluation of a measurement model needs to address internal consistency (composite reliability), indicator reliability, convergent validity (average variance extracted), and discriminant validity. In the following, we present the results of each statistic required to assess potential measurement errors of the measurement model.

Internal consistency reliability, the analysis that each item of the construct performs consistently, was measured using both Cronbach's alpha and composite reliability. The composite reliability varies between 0 and 1, with higher values indicating higher levels of reliability, and it is generally interpreted in the same way as Cronbach's alpha. Composite reliability values of 0.60 to 0.70 are acceptable in exploratory research, while in the more advanced stages of research, values between 0.70 and 0.90 can be regarded as satisfactory (Nunally $\&$ Bernstein, 1994). A value above 0.95 , however, indicates unnecessary redundancy in the construct items, which was the case in the attitude construct. Therefore, we omitted item ATT2 to decrease the composite reliability to below 0.95 . After this adjustment, the composite reliability varied between 0.80 and 0.949 , indicating acceptable reliability. Cronbach's alpha varied between 0.66 and 0.94 , again indicating an acceptable level for exploratory research (Figure 6).

Convergent validity (indicator reliability) is assessed by considering the outer loadings of the indicators and the average variance extracted (AVE). High loadings indicate that measurement items correctly measure the same phenomenon and share high proportion of variance. AVE is the degree to which a latent construct explains the variance of its indicators. (Hair et al. 2014). Items with an outer loading below 0.4 were omitted (e.g., one item in the Unobtrusiveness construct). The outer loadings should be 0.7 or higher, although according to Hair et al. (2014), items loading between 0.4 and 0.7 should only be removed if they improve composite reliability or if the AVE is above the suggested values. Even though the Insight construct was a validated measurement instrument, it posed difficulties with the outer loadings. Therefore, we removed three items out of the original eight $(1,2$, and 4$)$ to reach the necessary level of AVE.

The discriminant validity of the constructs was assessed using a cross-loading matrix (Appendix II). Based on the cross-loadings, all the constructs loaded onto their associated constructs. Fornell - Larcker analysis confirmed the discriminant validity; the square root of each construct's AVE is clearly higher than the correlation of that construct with any other construct. Figure 6 summarizes, that all measurement model criteria have been met.

\begin{tabular}{lll|lcccccccc} 
& CR & CA & AVE & 1 & 2 & 3 & 4 & 5 & 6 & 7 & 8 \\
\hline 1. Attitude & 0.945 & 0.912 & 0.852 & $\mathbf{0 . 9 2 3}$ & & & & & & &
\end{tabular}




\begin{tabular}{lll|lllllllllll} 
2. Dialogue support & 0.858 & 0.788 & 0.602 & 0.457 & $\mathbf{0 . 7 7 6}$ & & & & & \\
3. Insight & 0.847 & 0.787 & 0.527 & 0.291 & 0.079 & $\mathbf{0 . 7 2 6}$ & & & & \\
4. Need for reflection & 0.949 & 0.935 & 0.755 & 0.207 & 0.333 & 0.297 & $\mathbf{0 . 8 6 9}$ & & & \\
5. Perceived credibility & 0.899 & 0.850 & 0.690 & 0.590 & 0.379 & 0.114 & 0.173 & $\mathbf{0 . 8 3 1}$ & & \\
6. Primary task support & 0.915 & 0.860 & 0.782 & 0.515 & 0.544 & 0.153 & 0.335 & 0.475 & $\mathbf{0 . 8 8 5}$ & \\
7. Social influence & 0.926 & 0.893 & 0.757 & 0.591 & 0.249 & 0.257 & 0.161 & 0.386 & 0.502 & $\mathbf{0 . 8 7 0}$ & \\
8. Unobtrusiveness & 0.804 & 0.656 & 0.582 & 0.581 & 0.275 & 0.266 & 0.097 & 0.500 & 0.358 & 0.337 & $\mathbf{0 . 7 6 3}$
\end{tabular}

Figure 6. Assessment of internal consistency reliability of the constructs $(C R=$ composite reliability and $C A=C r o n b a c h$ 's alpha). Convergent reliability is demonstrated by values of AVE and Fornell-Larcker analysis. The bolded values show the square roots of $A V E$ and inter-construct correlations.

\subsection{Structural model and hypotheses testing}

After the measurement model was confirmed both reliable and valid, we proceeded to assess the structural model. PLS-SEM structural models are not measured by goodness of fit like CB-SEM models; instead, the model is evaluated based on how well it predicts endogenous (dependent) constructs. That was tested by defining the path coefficients and explained variances. We used the complete bootstrapping method with 5,000 resamples and parallel processing with no sign changes. The confidence interval method was the two-tailed bias-corrected and accelerated (BCa) bootstrap (default). Figure 7 reports the path coefficients, significances, and $\mathrm{R}$ squares for the endogenous constructs.

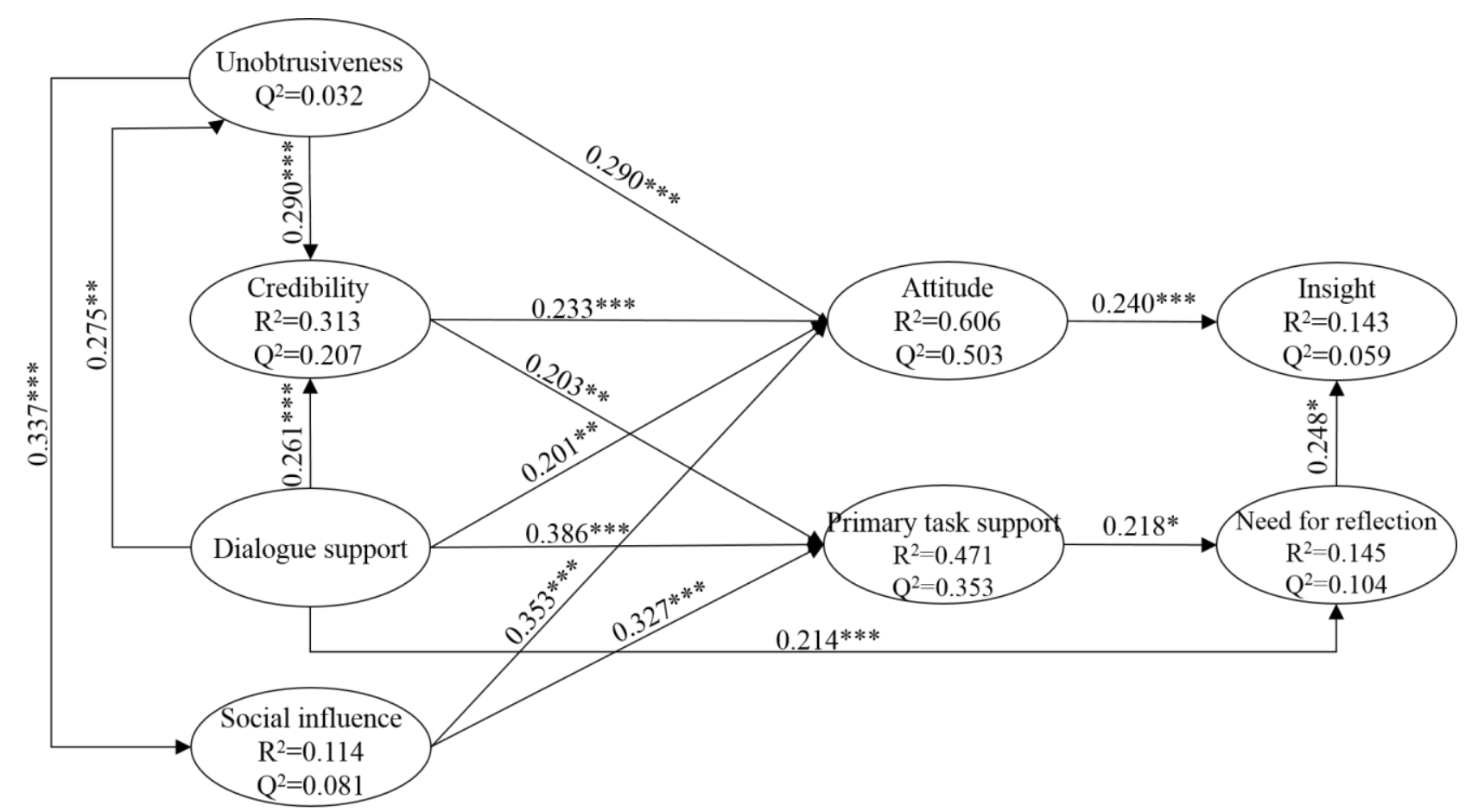

Figure 7. Structural model results of the full sample with path coefficients and their significances; also, the $R$ squares for endogenous constructs are presented. 
Social influence, credibility, and dialogue support explained $47 \%$ of the variance in primary task support. Dialogue support, unobtrusiveness, credibility, and social influence together accounted for $61 \%$ of the variance in the attitude construct. Unobtrusiveness and dialogue support accounted for $31 \%$ of variance in credibility, and unobtrusiveness alone explained $11 \%$ of the social influence construct. Primary task support explained $15 \%$ of the need for the self-reflection construct, and need for self-reflection and attitude together account for $14 \%$ of the variance in insight.

\section{Total effects and effect sizes}

By calculating the effect size (Cohen $\mathrm{f}^{2}$ ), one can assess an exogenous construct's contribution to an endogenous latent variable's $\mathrm{R}^{2}$ value. The $\mathrm{f}^{2}$ values of $0.02,0.15$, and 0.35 indicate an exogenous construct's small, medium, or large effect, respectively, on an endogenous construct. All effects were considered relevant (Cohen, 1988), and five effects were of medium relevance (Figure 8), leading to the conclusion that the model has practical relevance. The model had several mediating constructs that increased the total effects of several constructs. Therefore, the total effects of the constructs are also reported.

\begin{tabular}{|c|c|c|c|c|c|c|c|}
\hline & Attitude & Insight & $\begin{array}{l}\text { Need for } \\
\text { reflection }\end{array}$ & $\begin{array}{l}\text { Perceived } \\
\text { credibility }\end{array}$ & $\begin{array}{l}\text { Primary task } \\
\text { support }\end{array}$ & $\begin{array}{l}\text { Social } \\
\text { influence }\end{array}$ & Unobtrusiveness \\
\hline Attitude & & $\begin{array}{l}0.240 \\
(0.064)\end{array}$ & & & & & \\
\hline $\begin{array}{l}\text { Dialogue } \\
\text { support }\end{array}$ & $\begin{array}{l}0.402 \\
(0.086)\end{array}$ & 0.176 & $\begin{array}{l}0.322 \\
(0.038)\end{array}$ & $\begin{array}{l}0.379 \\
(0.092)\end{array}$ & $\begin{array}{l}0.493 \\
(0.237)\end{array}$ & 0.093 & $\begin{array}{l}0.275 \\
(0.082)\end{array}$ \\
\hline $\begin{array}{l}\text { Need for } \\
\text { reflection }\end{array}$ & & $\begin{array}{l}0.248 \\
(0.069)\end{array}$ & & & & & \\
\hline $\begin{array}{l}\text { Perceived } \\
\text { credibility }\end{array}$ & $\begin{array}{l}0.233 \\
(0.089)\end{array}$ & 0.067 & 0.044 & & $\begin{array}{l}0.203 \\
(0.060)\end{array}$ & & \\
\hline $\begin{array}{l}\text { Primary task } \\
\text { support }\end{array}$ & & 0.054 & $\begin{array}{l}0.218 \\
(0.039)\end{array}$ & & & & \\
\hline Social influence & $\begin{array}{l}0.353 \\
(0.257)\end{array}$ & 0.102 & 0.071 & & $\begin{array}{l}0.327 \\
(0.170)\end{array}$ & & \\
\hline Unobtrusiveness & $\begin{array}{l}0.509 \\
(0.154)\end{array}$ & 0.133 & 0.043 & $\begin{array}{l}0.428 \\
(0.247)\end{array}$ & 0.197 & $\begin{array}{l}0.337 \\
(0.128)\end{array}$ & \\
\hline
\end{tabular}

Figure 8. Total effects and effect sizes (Cohen's $f^{2}$ )

Notes: For all total effects, $\mathrm{p}<0.05$. Non-significant total effects are not reported. Effect sizes are shown in parentheses.

\section{Predictive validity}

The predictive validity of the model was assessed using Stone-Geisser's cross-validated redundancy measure $\mathrm{Q}^{2}$ with omission distance 8 (Figure 9.) Values above zero indicate that the construct has some predictive 
relevance. Predictive relevance was demonstrated for all endogenous constructs. Attitude, credibility, and primary task support exhibited rather strong predictive validity. The need for reflection also indicated its applicability in prediction.

\begin{tabular}{|c|c|c|c|c|c|}
\hline Attitude & Insight & $\begin{array}{l}\text { Need for } \\
\text { reflection }\end{array}$ & $\begin{array}{l}\text { Perceived } \\
\text { credibility }\end{array}$ & $\begin{array}{l}\text { Primary task } \\
\text { support }\end{array}$ & Social influence Unobtrusiveness \\
\hline 0.503 & 0.059 & 0.104 & 0.207 & 0.353 & 0.081 \\
\hline
\end{tabular}

Figure 9. $Q^{2}$ values assessing the predictive validity of the model.

\subsection{Subgroup analysis}

Subgroup analysis was done to study changes in both coefficients (Figure 10) and variances (Figure 11). We ran the PLS analysis with data groups and bootstrapping in a similar way, using 5,000 subsamples. Visual analysis revealed several differences between genders. The most drastic differences clustered around the perceived credibility and social influence constructs. Among females alone, the paths from dialogue support to perceived credibility, from credibility to attitude, from social influence to primary task support, and from unobtrusiveness to social influence were significant $(\mathrm{p}<0.000)$. Perceived credibility was found to influence primary task support only in males. The subgroups defined by usage time (up to 12 months and more than 12 months) also differed most in the influence of unobtrusiveness on social influence, which was significant for females only. The need for reflection influenced insight significantly among daily users.

\begin{tabular}{|c|c|c|c|c|c|c|c|c|c|}
\hline & $\begin{array}{l}\text { Females } \\
n=88\end{array}$ & $n=59$ & $\begin{array}{l}\text { Below } 12 \\
\text { months } \\
n=71\end{array}$ & $\begin{array}{l}\text { At least } 12 \\
\text { months } \\
n=76\end{array}$ & $\begin{array}{l}\text { Under } 30 \\
\text { years } \\
n=82\end{array}$ & $\begin{array}{l}30 \text { years } \\
\text { and older } \\
n=65\end{array}$ & $\begin{array}{l}\text { Daily } \\
\text { users } \\
n=47\end{array}$ & $\begin{array}{l}\text { Weekly } \\
\text { users } \\
n=100\end{array}$ & $\begin{array}{l}\text { Full } \\
\text { model } \\
N=147\end{array}$ \\
\hline ATT $\rightarrow$ INSI & $0.238^{*}$ & $0.401 \mathrm{~ns}$ & $0.016 \mathrm{~ns}$ & $0.354 * *$ & $0.235^{*}$ & $0.262 \mathrm{~ns}$ & $0.164 \mathrm{~ns}$ & $0.320 * *$ & $0.240 * *$ \\
\hline $\mathrm{DIAL} \rightarrow \mathrm{ATT}$ & $0.233 * *$ & $0.148 \mathrm{~ns}$ & $0.236^{*}$ & $0.193 \mathrm{~ns}$ & $0.237 * *$ & $0.184 \mathrm{~ns}$ & $0.331 *$ & $0.144 \mathrm{~ns}$ & $0.201 * *$ \\
\hline $\mathrm{DIAL} \rightarrow \mathrm{NEEDSR}$ & $0.289 * *$ & $0.036 \mathrm{~ns}$ & $0.212 \mathrm{~ns}$ & $0.166 \mathrm{~ns}$ & $0.163 \mathrm{~ns}$ & $0.341 *$ & $0.167 \mathrm{~ns}$ & $0.185^{*}$ & $0.214 * *$ \\
\hline $\mathrm{DIAL} \rightarrow \mathrm{CRED}$ & $0.378 * * *$ & $0.106 \mathrm{~ns}$ & $0.271 *$ & $0.252 * *$ & $0.317 * *$ & $0.220^{*}$ & $0.189 \mathrm{~ns}$ & $0.313 * * *$ & $0.261 * * *$ \\
\hline $\mathrm{DIAL} \rightarrow \mathrm{PRIM}$ & $0.365 * *$ & $0.523 * * *$ & $0.273 *$ & $0.460 * * *$ & $0.274 * *$ & $0.500 * *$ & $0.298 \mathrm{~ns}$ & $0.424 * * *$ & $0.386 * * *$ \\
\hline $\mathrm{DIAL} \rightarrow \mathrm{UNOB}$ & $0.261 *$ & $0.347 *$ & $0.374 * *$ & $0.242 \mathrm{~ns}$ & $0.258^{*}$ & $0.290 *$ & $0.140 \mathrm{~ns}$ & $0.321 * *$ & $0.275^{* *}$ \\
\hline $\mathrm{NEEDSR} \rightarrow \mathrm{INSI}$ & $0.254^{*}$ & $-0.183 n s$ & $0.361 \mathrm{~ns}$ & $0.276^{*}$ & $0.352 * *$ & $0.127 \mathrm{~ns}$ & $0.451 * * *$ & $0.095 \mathrm{~ns}$ & $0.248 *$ \\
\hline $\mathrm{CRED} \rightarrow \mathrm{ATT}$ & $0.287 * *$ & $0.107 \mathrm{~ns}$ & $0.242 *$ & $0.201 *$ & $0.235 * *$ & $0.197 \mathrm{~ns}$ & $0.251 \mathrm{~ns}$ & $0.238 * *$ & $0.233 * * *$ \\
\hline $\mathrm{CRED} \rightarrow \mathrm{PRIM}$ & $0.010 \mathrm{~ns}$ & $0.376 * * *$ & $0.239 \mathrm{~ns}$ & $0.193 *$ & $0.306^{*}$ & $0.129 \mathrm{~ns}$ & $0.192 \mathrm{~ns}$ & $0.191 \mathrm{~ns}$ & $0.203 * *$ \\
\hline $\mathrm{PRIM} \rightarrow$ NEEDSR & $0.316 * *$ & $0.106 \mathrm{~ns}$ & $0.024 \mathrm{~ns}$ & $0.385 * *$ & $0.201 \mathrm{~ns}$ & $0.140 \mathrm{~ns}$ & $0.050 \mathrm{~ns}$ & $0.316^{* *}$ & $0.218^{*}$ \\
\hline $\mathrm{SOC} \rightarrow \mathrm{ATT}$ & $0.367 * * *$ & $0.405 * * *$ & $0.414 * * *$ & $0.313^{* *}$ & $0.465 * * *$ & $0.249 * *$ & $0.272 *$ & $0.375 * * *$ & $0.353 * * *$ \\
\hline $\mathrm{SOC} \rightarrow \mathrm{PRIM}$ & $0.502 * * *$ & $0.120 \mathrm{~ns}$ & $0.341 * *$ & $0.293 * *$ & $0.304 * *$ & $0.288^{*}$ & $0.426 * *$ & $0.311 * * *$ & $0.327 * * *$ \\
\hline $\mathrm{UNOB} \rightarrow \mathrm{ATT}$ & $0.182^{*}$ & $0.463 * *$ & $0.216^{*}$ & $0.336 * *$ & $0.188^{*}$ & $0.408 * *$ & $0.247 \mathrm{~ns}$ & $0.313 * *$ & $0.290 * * *$ \\
\hline $\mathrm{UNOB} \rightarrow \mathrm{CRED}$ & $0.349 * * *$ & $0.560 * * *$ & $0.349 * * *$ & $0.515 * *$ & $0.348 * * *$ & $0.481 * * *$ & $0.465 * *$ & $0.430 * * *$ & $0.428 * * *$ \\
\hline
\end{tabular}




\begin{tabular}{l|llllllllll}
$\mathrm{UNOB} \rightarrow \mathrm{SOC}$ & $0.405^{* * *}$ & $0.176 \mathrm{~ns}$ & $0.446 * * *$ & $0.212 \mathrm{~ns}$ & $0.364 * * *$ & $0.310^{*}$ & $0.345^{* *}$ & $0.319^{* *}$ & $0.337 * * *$ \\
\hline
\end{tabular}

Figure 10. Path coefficients ( $\beta$ ) for the subgroup samples and the full sample

The explained variances for subgroups (Figure 11) were also only analyzed visually. Primary task support and dialogue support explained $27 \%$ of variance in the need for reflection among females, while there were no significant influences on the need for reflection for males. For males, dialogue support and perceived credibility accounted for $61 \%$ of variance in primary task support, compared to only $48 \%$ for females, explained by dialogue support and social influence. The values for attitude were similar, but while males' attitudes were influenced only by unobtrusiveness and social influence, females' attitudes were influenced by unobtrusiveness, social influence, dialogue support, and perceived credibility. For the younger users, both attitude and need for reflection explained $23 \%$ of variance in insight. For older users, there were no significant influences on insight.

\begin{tabular}{|c|c|c|c|c|c|c|c|c|c|}
\hline & $\begin{array}{c}\text { Females } \\
n=88\end{array}$ & $\begin{array}{l}\text { Males } \\
n=59\end{array}$ & $\begin{array}{c}\text { Below } 12 \\
\text { months } \\
n=71\end{array}$ & $\begin{array}{l}\text { At least } \\
12 \text { months } \\
n=76\end{array}$ & $\begin{array}{l}\text { Under } 30 \\
\text { years } \\
n=82\end{array}$ & $\begin{array}{c}30 \text { years } \\
\text { and older } \\
n=65\end{array}$ & $\begin{array}{l}\text { Daily } \\
\text { users } \\
n=47\end{array}$ & $\begin{array}{l}\text { Weekly } \\
\text { users } \\
\quad n=100\end{array}$ & $\begin{array}{l}\text { Full } \\
\text { model } \\
\qquad N=147\end{array}$ \\
\hline Attitude & 0.624 & 0.654 & 0.656 & 0.564 & 0.665 & 0.585 & 0.578 & 0.626 & 0.606 \\
\hline Insight & 0.171 & 0.208 & & 0.251 & 0.230 & & 0.253 & 0.124 & 0.143 \\
\hline Need for SR & 0.271 & & & 0.260 & & & & 0.202 & 0.145 \\
\hline Perceived credibility & 0.333 & 0.366 & 0.266 & 0.391 & 0.279 & 0.341 & 0.277 & 0.369 & 0.313 \\
\hline Primary task support & 0.477 & 0.609 & 0.393 & 0.550 & 0.438 & 0.522 & 0.462 & 0.495 & 0.471 \\
\hline Social influence & 0.164 & & 0.199 & & & & & & 0.114 \\
\hline Unobtrusiveness & & & & & & & & & \\
\hline
\end{tabular}

Figure 11. Variances explained $\left(R^{2}\right)$ for the subgroup samples and the full sample. Only significant values are reported.

\section{DISCUSSION}

In Finland, 22\% of men and 21\% of women have used a wellness or sports application on their smartphones to measure their physical activity. Higher rate of use of such applications is associated with students, those possessing a high level of education, and those living in metropolitan areas (Suomen virallinen tilasto (SVT), 2015). Our questionnaire also contained another set of questions in addition to demographic and service use questions. As such, it was quite extensive and took approximately 20-25 minutes to complete. We detected that over 500 users had opened the link to the questionnaire, but only 176 submitted responses. This implies some non-response bias. We believe that there were several reasons for non-response. Firstly, the length of the questionnaire required a certain level of persistence and interest in the topic. Secondly, the questions may have been unsuitable to users of several different systems that complement each other. We tried to address the latter issue by explicitly stating that one should select only one system and respond to questions based on that. Finally, the questionnaire was only in English. For some, this most likely increased the cognitive load for 
finalizing the survey. However, when adjusting the amount of received responses by the amount of use of these services in Finland, the response rate was around $4.5 \%$. This relatively low response rate restricts the generalizability of our findings to users, that in addition to interest in studied applications and regular usage habits, are also motivated enough to answer lengthy questionnaires. There is a connection between reflective capacity and need for cognition (van Seggelen-Damen, 2013) and therefore, our study most probably captured individuals with relatively high need for cognition. One can speculate if regular users of personal informatics tools always have that trait, but we believe that our approach adds to understanding of interaction between reflection and system features and is therefore applicable to system design in more diverse user groups. In addition, it is noteworthy that there are no reliable information on regular use rate of these applications.

Roughly, about half of the regular users used special trackers to measure their activity. In addition to this, several users relied on smartphone sensors for tracking, such as Sports Tracker and RunKeeper. These results indicate that users consider applications utilizing smartphone sensing to be sufficient for their needs and that the use of additional trackers does not give the full picture of health and wellness services used. In addition, the prevalence of mobile applications was surprisingly high (over $70 \%$ used only mobile applications) but in line with overall mobile device usage trends indicating that $89 \%$ of time spent in media content is done via mobile applications instead of mobile web (Chaffey, 2015).

Our main research question pondered whether the need for self-reflection and insightful understanding of one's own feelings and behaviors are traceable to PSD model constructs. The results from our full sample lend support to the hypotheses that dialogue support and primary task support influence the need for reflection. This is an interesting finding because dialogue support and primary task support are among the core elements of the persuasive systems model, and this result implies that the model has the capacity to evaluate and guide the design for reflective behavior change systems as well. However, the influence of dialogue support on the need for reflection is not very prominent and even disappears in most subgroups. In general, it is stronger for females. This implies either that the systems support certain types of dialogues that females find useful or that our measurement items are not fully capturing the phenomenon. The significant paths from dialogue support to need for reflection for users over 30 years old and weekly users imply that dialogue support has role that is not only gender factor but also goes deeper into system features. Relationship between primary task support and the need for reflection shows similar trends: it is stronger for females but also significant in some other subgroups. It is noteworthy that the level of need for reflection was slightly lower for males in general, supporting the idea that the values and motivational factors behind engagement with these tools might be different. For insight construct, the case is a bit different: there were no significant differences in levels of insight among subgroups, but for daily users, the model explains over $25 \%$ of variance in insight, compared to only $14 \%$ for full model. Overall, relatively low R square levels for need for reflection and insights construct 
call for further studies and better contextualization of the measurement items but the results imply they are useful in understanding the interactions between system features.

Previous studies (Lehto et al., 2012a; Lehto et al., 2012b; Lehto \& Oinas-Kukkonen, 2015) have reported strong support for the hypotheses that dialogue support influences both primary task support and perceived credibility of the system. In addition, our study found strong significance in the full sample model for both pathways of influence, even though the previous studies have focused on web-based systems and most of our users used only mobile applications. Our empirical data revealed that dialogue support's influence on perceived credibility was significant only for females. Previous work reports this as well but only in explained variances, not in path coefficients; for males, dialogue support explained only $27 \%$ of the variance in perceived credibility, compared to $51 \%$ for females (Lehto et al., 2012b). One should be cautious when comparing explained variances between studies, but this implies that difference by gender is not an entirely new finding here. Unfortunately, other similar studies have not assessed gender as a moderator.

When considering the explained variances of endogenous constructs in our model, we found further implications for gender differences. Interestingly, dialogue support and perceived credibility explain $61 \%$ of the variance in primary task support for males; for females $48 \%$ of variance in primary task support is accounted for by dialogue support and social influence, and there is no significant direct effect of credibility on primary task support. The variance in perceived credibility is nearly as large in both subgroups; however, for males credibility is affected only by unobtrusiveness, while for females it is affected also by dialogue support. This demands further research. What actually contributes to perceived credibility for males? Previous research has identified design aesthetics as one source of perceived credibility (Lehto et al., 2012a). Overall, the relationship between dialogue support and perceived credibility fluctuates in our subgroup analysis, performing both as highly significant and non-significant, making it even more important to understand its nature. Construct assessing the contextual fit of the system, unobtrusiveness, exerts strong influence on credibility throughout all the subgroups. Unobtrusiveness also shows the highest detected total effect found in this study in the influence of unobtrusiveness on attitude. Furthermore, attitude had the highest predictive validity for the model. We want to emphasize the importance of these features as mediators in any behavior change, informing how systems actually work (Hekler, Klasnja, Froehlich, \& Buman, 2013).

Only two dialogue support hypotheses out of five are significant for males. For comparison, all dialogue support hypotheses are significant for females. These results suggest either that the role of dialogue support is more crucial for females or that the dialogue features of the studied systems strengthen neither credibility nor attitude among males. Overall, the model explained approximately the same amount of variance for both genders (32\%), but 15 out of 17 hypotheses were supported for females, while only eight were supported for 
males. This implies that there are gender differences in the ways the systems support their users and that the model for males and females looks different.

Our exploratory results for subgroups suggest that the basic PSD model constructs, in addition to the model supplemented with self-reflection and insight, explain more of the variations for traditional fitness trackers used on a weekly basis compared to activity tracking and daily use. While the trend in personal informatics seems to emphasize continuous monitoring and support for activity in everyday life, both types deserve solid theoretical bases for how to build effective tools. Unfortunately, our empirical data is not sufficient to elaborate the differences between activity and fitness tracking in a reliable way. However, some preliminary conclusions are drawn from daily $(n=47)$ and weekly $(n=100)$ users, which are the most objective subgroup structures with which to reflect the actual use of the systems. We found that for daily users, a strong need for self-reflection also leads to insight, but weekly users miss this effect. However, none of the constructs utilized significantly contributes to the need for self-reflection among daily users. For weekly users, both dialogue support and primary task support significantly influence the need for self-reflection. This implies that either the needs for self-reflection and increased insight are innate among daily users or that daily use implies an intensive phase of system use, and users are, therefore, actively engaging with their data. Alternatively, daily use may imply habitual system use. Overall, for weekly users, the system seems to support the need to be self-reflective, but the model and measurements used fail to support daily activity tracking in a similar way. This has clear practical implications for the design and construction of new, more suitable measurement items. Overall, we can conclude that our empirical data are in line with existing research despite our study's focus on mobile applications and concurrent analysis of several different systems for behavior change. This implies that the field of behavior change technologies is rather mature or, at least, exploits rather similar methodologies. This also calls for an understanding of how these systems could rise to the next level.

\subsection{Theoretical implications}

Our results support previous research on the somewhat fuzzy connections between self-reflection and insight. Although we detected the influence of the need for reflection on insight, which was also found in previous studies (Roberts \& Stark, 2008), the influence was not very strong. This connection vanished in some subgroups (e.g., among males), but it was stronger for younger participants and daily users. Therefore, we consider both constructs valid items for future research. However, we aim to focus on the similarities between these and other constructs that measure cognitive indicators of change, possibly rephrasing and further developing them to suit our purposes. Grant has demonstrated that reflective coaching can increase the level of personal insight (2008), implying that insight is at least partly malleable via interventions. At the same time, some individuals face challenges in transforming reflective practices into actionable items and begin to ruminate on their problems, unable to make changes. Measuring reflection alone may, therefore, be a fruitless approach unless its relationship towards goal-attainment is properly assessed (Grant, 2003). In our data, need 
for reflection explained insight best for daily users and calls for further theoretical understanding on mechanisms of daily use: if insight is more easily achieved in daily engagement, which specific features support it? Our model did not fit very well for daily users. Overall, embedding constructs such as those we have used into intervention studies gathers valuable empirical data that have the potential to contribute to the behavioral theories used in HCI research and cultivate true interdisciplinary discourse to address real-world problems.

\subsection{Practical implications}

This study yields several important findings that will contribute to the development of the PSD model for the evaluation and design of future systems. For example, the current model fits better with traditional fitness trackers. We need to develop measurement items to capture the true nature of activity tracking. When such items are available, one can more thoroughly evaluate the overall persuasive user experience of activity tracking tools and further understand how those should be built. Daily monitoring and support is the most promising approach for changing behavioral patterns that are detrimental to health. It also holds promise for health care by providing information that is more objective on patients' everyday life activities and lifestyles. Our subgroup analysis on daily and weekly users implies that daily users have stronger relationship between reflection and insight. Therefore, daily engagement with the support services should be the focus also in research and development of persuasive systems.

Our results confirm that behavior change systems share many similar features, and one can study them as a collection of different systems. This indicates some level of maturation among behavior change technologies. At the same time, these tools are failing many users. While rather solid knowledge base on how to build these systems is now established, the HCI community must still strive for significant improvements. This is achievable via building on relevant theories and upgrading the level of technical implementation. We consider studies targeting existing systems very suitable for this work and encourage researchers and practitioners working together to build theory-based systems that meet the standards of outstanding interactive systems in the field. The practice of building these systems still needs to move on to assess how different designs affect the reflection process (Baumer, 2015) and utilize that knowledge more systematically.

Also the newly introduces scales used in this study (i.e., need for reflection and insight) should be developed further to be used to measure the process of behavior change. A limitation here is the fact that using selfreporting methods is not always very reliable, but if the system does aid in promoting reflection and insight, this influence should be visible in some measurement. The malleability of the measurements is relatively easy to assess in intervention studies, and we call for researchers to include these or similar constructs in their studies. One interesting research approach is, for example, to address if automation decreases not only 
engagement with data (Li et al., 2011) but also the insightful nature of the reflection process. Reflective activity rarely is the final goal of interventions, but we assume that different reflective thinking provokes different kind of actions. Therefore, it is of outmost importance to understand how software features and interactions between them change reflection and gained insights. It paves the way towards tailored and personalized services and enables adaptive functions. We also see psychological constructs as contributors that aid in understanding the meaning of other measured items, such as log data information. When collecting log data intentionally designed to reveal how and when different parts of the system are used, we can study if, for example, results are better for users spending time on summary statistics or for those responding to reflective questions. Alternative designs may also reveal if different design solutions alter the nature of the reflective thinking process. Our results indicate that practitioners should especially focus on dialogue support features when designing for reflection. It also has prominent role in forming the attitude and credibility towards the system that makes it very powerful in shaping the overall user experience. Understanding which features of the system are crucial for certain results narrows somewhat the design space, which is useful especially for adaptive and contextually aware systems. This means that we will be able to focus on things that matter. Finally, our results call for additional focus on factors that cause such a strong gender moderation for these tools. Is it truly a gender issue or some psychological or contextual element that is currently unacknowledged?

\subsection{Methodological implications}

There are two prominent approaches to SEM: covariance-based (CB-SEM) and component-based, utilizing partial least squares (PLS). In principle, CB-SEM is for theory-testing and PLS-SEM for theory development and prediction. Lately, PLS-SEM has become more popular among several disciplines. PLS-SEM aims to maximize explained variance in dependent constructs and evaluates the data quality via measurement model. The main arguments for choosing PLS-SEM over CB-SEM are its suitability for smaller sample size, nonnormal data, both formative and reflective indicators and high-complexity models (Ringle, Sarstedt, \& Straub, 2012; Urbach \& Ahlemann, 2010). Some of these arguments, however, have been questioned but also assessed in proper manner (Goodhue, Lewis, \& Thompson, 2012; Ringle et al., 2012). Overall, the current status of PLS-SEM use in information systems research is that PLS-SEM is acceptable solution but needs to be used in rigorous way. For example, editor's comment in highly prestigious MIS Quarterly concludes, that most of the criticism is actually more related to misuse of the PLS-SEM than the actual technique itself. On the other hand, PLS-SEM is freshly created method and needs to be further developed, which happens by studying and using it in practice. (Ringle et al., 2012). When the properties of the data restrict the use of CB-SEM, PLS-SEM is, therefore, appropriate alternative (Hair, Ringle, and Sarstedt, 2011). For HCI research, PLS-SEM seems to be very suitable and its predictive capabilities feed the design practice. It also serves as evaluation tool, in parallel with other usability analysis methods. However, its reporting technique is heavy and the field would benefit from studies that suggest alternative, more applied ways to present its results. 


\subsection{Limitations}

Our survey participants were students and personnel of a Finnish university. It is acknowledged that people with higher levels of education use these systems more frequently than does the average citizen. Our sample represents, therefore, only a limited fraction of the socio-economic groups living in Finland. Self-selected participants represent, most likely, a proportion with relatively high motivation and interest in pondering their usage habits. The used data set is also acquired by self-reporting tool. Furthermore, compared to most of the other studies in the field, our study focused on several different commercial systems. We assume that this intentional approach weakens some of the signals but validates our methodology in terms of evaluating trends and practices in real-life contexts.

\section{CONCLUSIONS}

In this study, we have used an existing conceptual framework and measurement instruments in an alternative context by measuring the persuasive system design factors in several behavior change systems at the same time. Additionally, our users used mainly mobile applications instead of the web-based technologies that were the primary focus of previous research. Regardless, our results are similar to those of previous studies using instruments derived from the PSD model and, therefore, lend support to the applicability of the model for heterogeneous systems designed for behavior change. This also indicates maturation in the field.

The structural modeling also implies that features present in PSD models can support reflection and promote insights that lead to personal behavior change. Persuasive features and reflective features are complementing each other rather than conflicting, and persuasive elements can increase the engagement toward insights. However, differences in traditional fitness trackers and activity trackers used for continuous monitoring seem to require somewhat different features to encourage self-reflective practices and insightful results. Finally, the strong effect of unobtrusiveness and attitude's remarkable predictive relevance highlight the impact of contextual fit and personal characteristics in the use of these systems.

\section{REFERENCES}

Adams, A. T., Costa, J., Jung, M. F., \& Choudhury, T. (2015). Mindless computing: designing technologies to subtly influence behavior. Proceedings of the 2015 ACM International Joint Conference on Pervasive and Ubiquitous Computing. New York: ACM.

Ajzen I (1991) The theory of planned behavior. Organ Behav Hum Decis Process 50(2):179-211

Azar, K. M. J., Lesser, L. I., Laing, B. Y., Stephens, J., Aurora, M. S., Burke, L. E., \& Palaniappan, L. P. (2013). Mobile applications for weight management: theory-based content analysis. American Journal of Preventive Medicine, 45(5), 583-9. doi:10.1016/j.amepre.2013.07.005

Baumer, E. P. (2015). Reflective informatics: conceptual dimensions for designing technologies of reflection. Proceedings of the ACM Conference on Human Factors in Computing Systems. New York: ACM. 
Baumer, E. P. S., Khovanskaya, V., Matthews, M., Reynolds, L., Sosik, V.S., \& Gay, G. (2014). Reviewing reflection: on the use of reflection in interactive system design. Proceedings of the 2014 Conference on Designing Interactive Systems. New Tork: ACM. doi:10.1145/2598510.2598598

Carr, S. E., \& Johnson, P. H. (2013). Does self reflection and insight correlate with academic performance in medical students? BMC Medical Education, 13(1), 113.

Chaffey, D. (2015). Statistics on mobile usage and adoption to inform your mobile marketing strategy. http://www.smartinsights.com/mobile-marketing/mobile-marketing-analytics/mobile-marketing-statistics/ Last accessed April 21, 2016.

Cohen, J. (1988). Statistical power analysis for the behavioral sciences. Mahwah, NJ: Lawrence Erlbaum.

Engberg, E., Liira, H., Kukkonen-Harjula, K., From, S., Kautiainen, H., Pitkala, K., \& Tikkanen, H. (2015). Associations of physical activity with self-rated health and well-being in middle-aged Finnish men. Scandinavian Journal of Public Health, 43(2), 190-196.

Fishbein M, Ajzen I (1975) Belief, attitude, intention, and behavior: an introduction to theory and research. Addison-Wesley, Reading.

Fleck, R., \& Fitzpatrick, G. (2010). Reflecting on reflection: framing a design landscape. Proceedings of the Conference of the Computer-Human Interaction Special Interest Group of Australia on Computer-Human Interaction. New York: ACM.

Fogg, B. J. (2003). Persuasive Technology: Using Computers to Change What We Think and Do. San Francisco: Morgan Kaufmann.

Goodhue, D. L., Lewis, W., \& Thompson, R. (2012). Does PLS have advantages for small sample size or nonnormal data?. MIS Quarterly, 36(3), 981-1001.

Gouveia, R., Pereira, F., Caraban, A., Munson, S. A., \& Karapanos, E. (2015). You have 5 seconds: designing glanceable feedback for physical activity trackers. Proceedings of the 2015 ACM International Joint Conference on Pervasive and Ubiquitous Computing and Proceedings of the 2015 ACM International Symposium on Wearable Computers. New York: ACM.

Grant, A. M. (2008). Personal life coaching for coaches-in-training enhances goal attainment, insight and learning. Coaching: An International Journal of Theory, Research and Practice, 1:1, 54-70. doi: $10.1080 / 17521880701878141$

Grant, A. M. (2003). The impact of life coaching on goal attainment, metacognition and mental health. Social Behavior and Personality: An International Journal, 31(3), 253-263.

Grant, A. M., Franklin, J., \& Langford, P. (2002). The self-reflection and insight scale: A new measure of private self-consciousness. Social Behavior and Personality: An International Journal, 30(8), 821-835.

Hair, J.F., Hult, G.T.M., Ringle, C.M., \& Sarstedt, M. (2013). A Primer on Partial Least Squares Structural Equation Modeling (PLS-SEM) (p. 283). SAGE Publications. Kindle Edition.

Hair, J. F., Ringle, C. M., \& Sarstedt, M. (2011). PLS-SEM: Indeed a silver bullet. Journal of Marketing theory and Practice, 19(2), 139-152.

Hair, J. F., Sarstedt, M., Ringle, C. M., \& Mena, J. A. (2012). An assessment of the use of partial least squares structural equation modeling in marketing research. Journal of the Academy of Marketing Science, 40(3), 414-433.

Hamari, J., Koivisto, J., (2013). Social motivations to use gamification: an empirical study of gamifying exercise. Proceedings of the 21st European Conference on Information Systems. Completed Research. Paper 105. http://aisel.aisnet.org/ecis2013_cr/105

Hammond, T. (2014). Wearables have a dirty little secret: 50\% of users lose interest. Tech Republic Inc. http://www.techrepublic.com/article/wearables-have-a-dirty-little-secret-most-people-lose-interest/ Last accessed April 21, 2016.

Harrington, R., \& Loffredo, D. A. (2011). Insight, rumination, and self-reflection as predictors of well-being. The Journal of Psychology, 145(1), 39-57.

Hekler, E. B., Klasnja, P., Froehlich, J. E., \& Buman, M. P. (2013). Mind the theoretical gap: interpreting, using, and developing behavioral theory in HCI research. Proceedings of the SIGCHI Conference on Human Factors in Computing Systems. New York: ACM.

Herz, J. (2014). Wearables are totally failing the people who need them most. Wired. http://www.wired.com/2014/11/where-fitness-trackers-fail/ Last accessed April 21, 2016.

Kohl, H.W., et al. (2013). The pandemic of physical inactivity: global action for public health. The Lancet, 380(9838), $294-305$. 
Ledger, D., \& McCaffrey, D. (2014). Inside wearables: How the science of human behavior change offers the secret to long-term engagement. Endeavour Partners 93, 1:36-45 (White Paper).

Lee, M. K., Kim, J., Forlizzi, J., \& Kiesler, S. (2015). Personalization revisited: a reflective approach helps people better personalize health services and motivates them to increase physical activity. Proceedings of the 2015 ACM International Joint Conference on Pervasive and Ubiquitous Computing. New York: ACM.

Lehto, T., \& Oinas-Kukkonen, H. (2011). Persuasive features in web-based alcohol and smoking interventions: a systematic review of the literature. Journal of medical Internet research, 13(3), e46.

Lehto, T., \& Oinas-Kukkonen, H. (2015). Explaining and predicting perceived effectiveness and use continuance intention of a behaviour change support system for weight loss. Behaviour \& Information Technology, 34(2), 176-189.

Lehto, T., Oinas-Kukkonen, H., \& Drozd, F. (2012a). Factors affecting perceived persuasiveness of a behavior change support system. ICIS 2012 Proceedings: Human behavior in IT adoption and use.

Lehto, T., Oinas-Kukkonen, H., Pätiälä, T., \& Saarelma, O. (2012b). Consumers' perceptions of a virtual health check: An empirical investigation. ECIS 2012 Proceedings.

Li, I., Dey, A., \& Forlizzi, J. (2010). A stage-based model of personal informatics systems. Proceedings of the International Conference on Human Factors in Computing Systems. doi:10.1145/1753326.1753409

Li, I., Dey, A. K., \& Forlizzi, J. (2011). Understanding My Data, Myself: Supporting Self-Reflection with Ubicomp Technologies. In Proceedings of the 13th international conference on Ubiquitous computing (pp. 405-414). ACM.

Lyke, J. A. (2009). Insight, but not self-reflection, is related to subjective well-being. Personality and Individual Differences, 46(1), 66-70.

Matthews, J., Win, K. T., Oinas-Kukkonen, H., \& Freeman, M. (2016). Persuasive Technology in Mobile Applications Promoting Physical Activity: a Systematic Review. Journal of Medical Systems, 40(3), 1-13.

Mezirow, J. (1991). Transformative dimensions of adult learning. San Francisco: Jossey-Bass.

Michie, S., Abraham, C., Whittington, C., McAteer, J., \& Gupta, S. (2009). Effective techniques in healthy eating and physical activity interventions: a meta-regression. Health Psychology, 28(6), 690-701. doi:10.1037/a0016136

Middelweerd, A., Mollee, J. S., van der Wal, C. N., Brug, J., \& Te Velde, S. J. (2014). Apps to promote physical activity among adults: a review and content analysis. International Journal of Behavioral Nutrition and Physical Activity, 11(1), 97.

Nunally, J. C., \& Bernstein, I. (1994). Psychometric Theory. New York: McGraw-Hill.

Oinas-Kukkonen, H. (2013). A foundation for the study of behavior change support systems. Personal and Ubiquitous Computing, 17(6), 1223-1235

Oinas-Kukkonen, H., \& Harjumaa, M. (2009). Persuasive systems design: key issues, process model, and system features. Communications of the Association for Information Systems, 24(1), 28.

Ploderer, B., Reitberger, W., Oinas-Kukkonen, H., \& van Gemert-Pijnen, J. (2014). Social interaction and reflection for behaviour change. Personal and Ubiquitous Computing, 18(7), 1667-1676.

Ringle, C. M., Sarstedt, M., \& Straub, D. (2012). A critical look at the use of PLS-SEM in MIS Quarterly. MIS Quarterly, 36(1).

Ringle, C. M., Wende, S., and Becker, J.M. (2015). "SmartPLS 3." Boenningstedt: SmartPLS GmbH. http://www.smartpls.com.

Roberts, C., \& Stark, P. (2008). Readiness for self-directed change in professional behaviours: factorial validation of the Self-reflection and Insight Scale. Medical Education, 42(11), 1054-1063.

Rogers, R. R. (2001). Reflection in Higher Education: A Concept Analysis. Innovative Higher Education, 26(1), 37-57. doi:10.1023/A:1010986404527

Siegel, M. A., \& Beck, J. (2014). Slow Change Interaction Design. Interactions, 21(1), $28-35$. doi:10.1145/2542649

Spagnolli, A., Chittaro, L., \& Gamberini, L. (2016). Interactive Persuasive Systems: A Perspective on Theory and Evaluation. International Journal of Human-Computer Interaction, 32(3), 177-189.

Stawarz, K., Cox, A. L., \& Blandford, A. (2015). Beyond self-tracking and reminders: designing smartphone apps that support habit formation. Proceedings of the ACM Conference on Human Factors in Computing Systems. New York: ACM.

Stein, D. \& Grant. A. M. (2014). Disentangling the Relationships Among Self-Reflection, Insight, and Subjective Well-Being: The Role of Dysfunctional Attitudes and Core Self-Evaluations. The Journal of Psychology, 148(5), 505-522. doi: 10.1080/00223980.2013.810128 
Suomen virallinen tilasto (SVT), (2015). Väestön tieto- ja viestintätekniikan käyttö. ISSN=2341-8699. 2015, Liitetaulukko 15. Reitti- ja paikannussovellusten ja kuntoilusovellusten käyttö matkapuhelimella, aktiivisuusrannekkeiden ja älykellojen käyttö viimeisen 3 kuukauden aikana iän, toiminnan, koulutusasteen, asuinpaikan kaupunkimaisuuden ja sukupuolen mukaan 2015, \%-osuus väestöstä . Helsinki: Tilastokeskus. Last accessed April 21, 2016. http://www.stat.fi/til/sutivi/2015/sutivi 2015 201511-26_tau_015_fi.html

Urbach, N., \& Ahlemann, F. (2010). Structural equation modeling in information systems research using partial least squares. JITTA: Journal of Information Technology Theory and Application, 11(2), 5.

Van Seggelen-Damen, I. C. M. (2013). Reflective Personality: Identifying Cognitive Style and Cognitive Complexity. Current Psychology 32(1), 82-99. doi:10.1007/s12144-013-9166-5

\section{$9 \quad$ Appendix I}

\begin{tabular}{|c|c|c|}
\hline Constructs & Items & Source \\
\hline Unobtrusiveness & $\begin{array}{l}\text { UNOB1 Using the service fits into my daily life } \\
\text { UNOB2 Using the service disrupts my daily routines } \\
\text { (deleted) } \\
\text { UNOB3 Using the service is convenient for me } \\
\text { UNOB4 Finding the time to use the service is not a } \\
\text { problem for me }\end{array}$ & Lehto et al., 2012a \\
\hline $\begin{array}{l}\text { Dialogue } \\
\text { support }\end{array}$ & $\begin{array}{l}\text { DIAL1 The service encourages me } \\
\text { DIAL2 The service rewards me } \\
\text { DIAL3 The service provides me with appropriate feedback } \\
\text { DIAL4 The service provides me with reminders for } \\
\text { reaching my personal goals }\end{array}$ & $\begin{array}{ll}\text { Lehto } \quad \& \quad \text { Oinas } \\
\text { Kukkonen, } 2015\end{array}$ \\
\hline $\begin{array}{l}\text { Perceived } \\
\text { credibility }\end{array}$ & $\begin{array}{l}\text { CRED1 The service is trustworthy } \\
\text { CRED2 The service is reliable } \\
\text { CRED3 The service shows expertise } \\
\text { CRED4 The service instills confidence in me }\end{array}$ & Lehto et al., 2012a \\
\hline $\begin{array}{l}\text { Primary task } \\
\text { support }\end{array}$ & $\begin{array}{l}\text { PRIM1 The service makes it easier for me to reach my } \\
\text { goals } \\
\text { PRIM2 The service helps me in reaching my goals } \\
\text { gradually } \\
\text { PRIM3 The service helps me in keeping track of my } \\
\text { progress }\end{array}$ & Lehto et al., 2012a \\
\hline Attitude & $\begin{array}{l}\text { ATT1 All things considered, I find using the service to be } \\
\text { a wise thing to do } \\
\text { ATT2 All things considered, I find using the service to be } \\
\text { a good idea (deleted) } \\
\text { ATT3 All things considered, I find using the service to be } \\
\text { a positive thing } \\
\text { ATT4 All things considered, I find the service to be } \\
\text { favorable to use }\end{array}$ & Hamari \& Kuusisto, 2013 \\
\hline
\end{tabular}




\begin{tabular}{|c|c|c|}
\hline Social influence & $\begin{array}{l}\text { SOC1 People who influence my attitudes would } \\
\text { recommend the service } \\
\text { SOC2 People who are important to me would think } \\
\text { positively of me using the service } \\
\text { SOC3 People whom I appreciate would encourage me to } \\
\text { use the service } \\
\text { SOC4 My friends would think using the service is a good } \\
\text { idea }\end{array}$ & Hamari \& Kuusisto, 2013 \\
\hline $\begin{array}{l}\text { Need } \\
\text { reflection }\end{array}$ & $\begin{array}{l}\text { NEED1 I am not really interested in analyzing my } \\
\text { behavior } \\
\text { NEED2 It is important for me to evaluate the things that I } \\
\text { do } \\
\text { NEED3 I am very interested in examining what I think } \\
\text { about } \\
\text { NEED4 It is important to me to try to understand what my } \\
\text { feelings mean } \\
\text { NEED5 I have a definite need to understand the way that } \\
\text { my mind works } \\
\text { NEED6 It is important for me to be able to understand how } \\
\text { my thoughts arise }\end{array}$ & $\begin{array}{l}\text { Grant et al., } 2002 \\
\text { (Need for self-reflection) }\end{array}$ \\
\hline Insight & $\begin{array}{l}\text { INSII I am usually aware of my thoughts (deleted) } \\
\text { INSI2 I'm often confused about the way that I really feel } \\
\text { about things (deleted) } \\
\text { INSI3 I usually have a very clear idea about why I've } \\
\text { behaved in a certain way } \\
\text { INSI4 I'm often aware that I'm having a feeling, but I often } \\
\text { don't quite know what it is (deleted) } \\
\text { INSI5 My behavior often puzzles me } \\
\text { INSI6 Thinking about my thoughts makes me more } \\
\text { confused } \\
\text { INSI7 Often I find it difficult to make sense of the way I } \\
\text { feel about things } \\
\text { INSI8 I usually know why I feel the way I do }\end{array}$ & Grant et al., 2002 \\
\hline
\end{tabular}

\section{Appendix II}

Cross-loadings assessing the discriminant validity

\begin{tabular}{|l|l|l|l|l|l|l|l|l|}
\hline & ATT & DIAL & INSI & SELFR & CRED & PRIM & SOC & UNOB \\
\hline ATT1 & $\mathbf{0 . 8 7 6}$ & 0.356 & 0.287 & 0.220 & 0.501 & 0.454 & 0.520 & 0.441 \\
\hline
\end{tabular}




\begin{tabular}{|c|c|c|c|c|c|c|c|c|}
\hline ATT3 & 0.942 & 0.453 & 0.248 & 0.203 & 0.524 & 0.484 & 0.545 & 0.581 \\
\hline $\begin{array}{l}\text { ATT4 } \\
\end{array}$ & 0.948 & 0.450 & 0.273 & 0.154 & 0.604 & 0.487 & 0.569 & 0.576 \\
\hline CRED1 & 0.553 & 0.220 & 0.137 & 0.076 & 0.857 & 0.408 & 0.319 & 0.467 \\
\hline CRED2 & 0.477 & 0.162 & 0.127 & 0.144 & 0.860 & 0.382 & 0.280 & 0.410 \\
\hline CRED3 & 0.491 & 0.400 & 0.027 & 0.162 & 0.821 & 0.358 & 0.325 & 0.429 \\
\hline CRED4 & 0.433 & 0.469 & 0.089 & 0.198 & 0.784 & 0.430 & 0.354 & 0.350 \\
\hline DIAL1 & 0.506 & 0.835 & 0.085 & 0.344 & 0.369 & 0.592 & 0.319 & 0.318 \\
\hline DIAL2 & 0.270 & 0.799 & -0.002 & 0.174 & 0.218 & 0.332 & 0.142 & 0.218 \\
\hline DIAL3 & 0.312 & 0.759 & 0.129 & 0.239 & 0.282 & 0.360 & 0.155 & 0.195 \\
\hline DIAL4 & 0.225 & 0.705 & -0.001 & 0.226 & 0.265 & 0.292 & 0.063 & 0.034 \\
\hline INSI3 & 0.142 & 0.048 & 0.703 & 0.333 & 0.081 & 0.059 & 0.176 & 0.155 \\
\hline INSI5 & 0.223 & 0.020 & 0.678 & 0.055 & 0.121 & 0.109 & 0.163 & 0.170 \\
\hline INSI6 & 0.198 & -0.005 & 0.667 & 0.115 & -0.044 & 0.078 & 0.148 & 0.120 \\
\hline INSI7 & 0.225 & 0.103 & 0.739 & 0.088 & 0.041 & 0.035 & 0.145 & 0.157 \\
\hline INSI8 & 0.272 & 0.093 & 0.831 & 0.327 & 0.158 & 0.217 & 0.258 & 0.302 \\
\hline SELFR1 & 0.122 & 0.259 & 0.222 & 0.785 & 0.135 & 0.215 & 0.118 & 0.086 \\
\hline SELFR2 & 0.170 & 0.285 & 0.297 & 0.846 & 0.168 & 0.230 & 0.123 & 0.151 \\
\hline SELFR3 & 0.229 & 0.347 & 0.217 & 0.896 & 0.211 & 0.394 & 0.169 & 0.121 \\
\hline SELFR4 & 0.255 & 0.237 & 0.282 & 0.901 & 0.180 & 0.356 & 0.219 & 0.130 \\
\hline SELFR5 & 0.122 & 0.265 & 0.258 & 0.881 & 0.093 & 0.258 & 0.082 & -0.039 \\
\hline SELFR6 & 0.160 & 0.337 & 0.275 & 0.898 & 0.108 & 0.270 & 0.117 & 0.050 \\
\hline PRIM1 & 0.411 & 0.507 & 0.152 & 0.362 & 0.388 & 0.896 & 0.409 & 0.318 \\
\hline PRIM2 & 0.456 & 0.515 & 0.150 & 0.348 & 0.407 & 0.933 & 0.446 & 0.332 \\
\hline PRIM3 & 0.507 & 0.416 & 0.100 & 0.165 & 0.475 & 0.821 & 0.483 & 0.300 \\
\hline SOC1 & 0.418 & 0.271 & 0.253 & 0.175 & 0.244 & 0.441 & 0.836 & 0.204 \\
\hline SOC2 & 0.496 & 0.155 & 0.243 & 0.156 & 0.394 & 0.444 & 0.900 & 0.298 \\
\hline SOC3 & 0.535 & 0.282 & 0.199 & 0.186 & 0.387 & 0.496 & 0.909 & 0.262 \\
\hline SOC4 & 0.588 & 0.167 & 0.207 & 0.052 & 0.306 & 0.368 & 0.833 & 0.393 \\
\hline UNOB1 & 0.511 & 0.182 & 0.262 & 0.071 & 0.459 & 0.314 & 0.325 & 0.850 \\
\hline UNOB3 & 0.510 & 0.304 & 0.192 & 0.105 & 0.422 & 0.283 & 0.248 & 0.802 \\
\hline UNOB4 & 0.221 & 0.100 & 0.131 & 0.028 & 0.184 & 0.208 & 0.171 & 0.616 \\
\hline
\end{tabular}

